\title{
The Immunoimaging Toolbox
}

\author{
Aaron T. Mayer ${ }^{1}$, and Sanjiv S. Gambhir ${ }^{1,2}$ \\ ${ }^{I}$ Department of Bioengineering, Stanford University, Stanford, California; and ${ }^{2}$ Department of Radiology, Department of Materials \\ Science and Engineering, Molecular Imaging Program at Stanford, Canary Center at Stanford for Cancer Early Detection, Stanford \\ University, Stanford, California
}

\begin{abstract}
The recent clinical success of cancer immunotherapy has renewed interest in the development of tools to image the immune system. In general, immunotherapies attempt to enable the body's own immune cells to seek out and destroy malignant disease. Molecular imaging of the cells and molecules that regulate immunity could provide unique insight into the mechanisms of action, and failure, of immunotherapies. In this article, we will provide a comprehensive overview of the current state-of-the-art immunoimaging toolbox with a focus on imaging strategies and their applications toward immunotherapy.
\end{abstract}

Key Words: molecular imaging; oncology; radioimmunoimaging; cell tracking; immune imaging; immunotherapy

J Nucl Med 2018; 59:1174-1182

DOI: 10.2967/jnumed.116.185967

\section{$\mathbf{T}$}

he recent clinical success of cancer immunotherapy has renewed interest in the development of tools to image the immune system. In general, immunotherapies attempt to enable the body's own immune cells to seek out and destroy malignant disease. Molecular imaging of the cells and molecules that regulate immunity could provide unique insight into the mechanisms of action, and failure, of immunotherapies. In this review, we will collectively refer to the tools applied toward imaging the immune system as the immunoimaging toolbox. The immunoimaging toolbox comprises imaging hardware, software, and biologic wetware that together enable dynamic and noninvasive visualization of immune response. Other recent reviews have focused on specific portions of the immunoimaging toolbox, including advances in imaging hardware (1) and certain classes of imaging probes $(2,3)$. Here, we will attempt to provide a comprehensive overview of the current state-of-the-art immunoimaging toolbox with a focus on imaging strategies and their applications toward immunotherapy. However, despite our comprehensive intent, there are many applications that cannot be discussed here because of space limitations.

We searched the PubMed database for articles using the terms immune imaging, imaging immunotherapy, and cell tracking. We considered all English-language articles published since 1990

Received Mar. 10, 2018; revision accepted May 21, 2018.

For correspondence or reprints contact: Sanjiv S. Gambhir, James H. Clark Center, Stanford University, 318 Campus Dr., East Wing, 1st Floor, Stanford, CA 94305.

E-mail: sgambhir@stanford.edu

Published online May 24, 2018.

COPYRIGHT (c) 2018 by the Society of Nuclear Medicine and Molecular Imaging. until the date this paper was submitted for publication, but articles published over the past 5-10 y were given priority.

\section{IMMUNOIMAGING STRATEGIES}

The immunoimaging toolbox has rapidly expanded over the last decade because of a shift in focus from imaging cancer and specific diseases to imaging a patient's underlying immune state. This paradigm shift has been driven in part by the failure of conventional imaging methods to accurately monitor and predict response to clinical immunotherapies. Because the success of immunotherapy is dependent on the generation of a robust immune response, immunoimaging tools are of high interest. Tables 1 and 2 summarize the current status of the immunoimaging toolbox by providing a comprehensive list of agents that have been used to image the immune system. The tables divide the immunoimaging toolbox into two strategic classes: probes targeted to endogenous immune cell biomarkers (Table 1) and direct and indirect approaches to immune cell labeling strategies (Table 2). Here, we discuss the implementation of each strategy toward imaging immune cells and molecules (Fig. 1).

\section{Probes Targeted to Endogenous Immune Cell Biomarkers}

This approach seeks to develop molecular imaging agents that bind to, or are selectively taken up by, endogenous immune molecules or immune cells, respectively. There are a wide variety of immune targets to choose from, many of which have been categorized by immunologists as cluster-of-differentiation (CD) markers. The expression of CD markers is spatially and temporally heterogeneous, and together, these markers define an immune cell phenotype. CD markers can be used to identify anything from general immune cell classes (e.g., CD3-positive T cells) to specific cell subsets (e.g., CD3-positive, CD4-positive, FoxP3-positive regulatory $\mathrm{T}$ cells) and immune cell states (e.g., CD3-positive, CD4-positive, CD25-positive, CD279-high, FOXP3-positive activated regulatory $\mathrm{T}$ cells). In addition to these $\mathrm{CD}$ markers, certain metabolic pathways are also selectively upregulated in immune cells. For example, both deoxyguanosine kinase and deoxycytidine kinase, implicated in nucleoside salvage pathways, have been identified as being highly upregulated in activated, as compared with resting, $\mathrm{T}$ cells. The identification and selection of immune biomarkers is an active and important area of research. Because of the natural presence of these immune markers, probes targeted for endogenous immune cell biomarkers provide a relatively straightforward immunoimaging approach.

Endogenous biomarker-targeting probes can be built from antibodies and other natural protein scaffolds, as well as developed de novo from chemical or protein engineering techniques. Large libraries of potential binders are often generated and screened against an immune target of interest. Because of the challenges 
of developing small-molecule chemical libraries, biologics (antibodies or their derivatives) have become a favorite option for imaging the immune system. Often, antibodies already under development for immunotherapeutic applications can quickly be modified for imaging via conjugation to a contrast agent or radionuclide. Another benefit of antibodies as imaging agents is their naturally high specificity and binding affinity toward their cognate antigen. Drawbacks to antibody imaging include their large size $(\sim 150 \mathrm{kDa})$, leading to slow clearance from nontarget tissues and relatively poor penetration into target tissues. When imaging with antibodies, a clinician must often wait several days before the background signal from unbound probe has cleared from various tissues and the circulation. To overcome these challenges, alternative biologic scaffolds are being developed and optimized for improved pharmacokinetics. Engineered antibody fragments such as minibodies, diabodies, and scFv fragments (4), and antibodies from other species such as camelid and shark, are all actively being explored (5). Endogenous ligands can be affinity-matured and modified to be used as probes ( 6 ), and aptamers, adnectins, and cystine knots add to a growing list of scaffolds that are being developed and applied toward immunoimaging. With all these potential scaffolds to choose from, one must weigh the trade-offs between specificity, sensitivity, and clearance. Mounting empiric data from preclinical studies and from mathematic models (7) should help identify the ideal scaffold choices for immunoimaging applications in the clinic.

\section{Immune Cell Labeling Strategies}

Direct labeling of immune cells ex vivo that have first been isolated from a patient is another commonly used immunoimaging technique. In this method, immune cells are incubated ex vivo with an imaging agent before being adoptively transferred back into the patient. The immune cells can then be tracked longitudinally by imaging over time. A wide range of immune cells has been monitored in this manner, including $\mathrm{T}$ cells, $\mathrm{B}$ cells, natural killer cells, dendritic cells, macrophage, monocytes, and hematopoietic stem cells. Although this strategy enables simple and specific labeling of almost any chosen immune cell of interest, it has several drawbacks. Many contrast agents used in this manner have a direct impact on cell function. For example, both indium oxine and ferumoxytol used for tracking cells via PET or MRI, respectively, are known to cause cell cytotoxicity at too high a concentration. Furthermore, once they are successfully labeled, there is a loss in sensitivity over time due to efflux or dilution of the probe during cell division. In clinical practice, this phenomenon limits the time that cells can be monitored to hours or weeks

\section{NOTEWORTHY}

- The immunoimaging toolbox is rapidly expanding and providing novel insight into the immune system and immune responses to therapy.

- Tables 1 and 2 provide a comprehensive overview of the current state-of-the-art immunoimaging toolbox.

- Clinical roles for the immunoimaging toolbox include guiding the rationale for drug development, informing optimal treatment strategies, improving patient stratification and trial design, providing early clinical response prediction, and monitoring therapeutic outcomes for better patient management. after adoptive transfer. Finally, once the cells have been transferred back into the patient, it is impossible to tell whether the immune cells are viable (a dead cell will still lead to signal with this technique), further confounding the interpretation of response. Nonetheless, direct labeling is an important imaging technique that has provided valuable insight into immune cell reconstitution and cell homing to sites of disease or damage.

Indirect labeling approaches overcome many of the challenges associated with direct labeling. This labeling strategy involves either viral transduction or transfection of a reporter gene into an immune cell of interest. A reporter gene can be anything from a luciferase (e.g., the enzyme used by fireflies to create their characteristic bioluminescent glow) to viral genes that code for enzymes not commonly found in the human body. A successful example has been herpes simplex virus type 1 thymidine kinase, which can subsequently be visualized using a reporter probe that is trapped by only cells expressing that reporter gene. Furthermore, reporter genes can be put downstream from promoters that turn on the expression of the gene only if an immune cell is activated. In this way, reporter gene strategies can reveal immune cell locations, viability, and activation state. Reporter genes have been developed for use with multiple imaging modalities, including MRI, PET, and optical imaging (8). Although indirect labeling techniques can theoretically be performed in vivo, challenges with specificity and concerns about viral gene editing in humans have limited their primary application to ex vivo immune cell manipulation. As with direct labeling techniques, it is critical to assess whether the introduction of the reporter gene is affecting the viability or function of the immune cell itself. Other issues with using viruses or transfection techniques, including challenges with stable expression and gene transcription "leakiness," as well as the need to remove cells from a patient, have partially limited the applications of this technique thus far. That said, as the safety and efficacy of certain viruses improve, we may see more widespread clinical adoption of this imaging technique due to the ability to image immune cells for their entire life span.

\section{IMMUNOIMAGING APPLICATIONS TOWARD IMMUNOTHERAPY}

The immunoimaging strategies discussed above are rapidly being deployed in an attempt to predict and monitor response to immunotherapy. In this section, we will review several classes of immunotherapy (Fig. 2) and provide examples of how immunoimaging is already being applied to better understand and characterize immune response (Fig. 3).

\section{Immune Checkpoint Blockade}

Immune checkpoint blockade has emerged as a promising immunotherapeutic treatment strategy for several malignancies. Under normal physiologic conditions, so-called immune checkpoints help prevent the immune system from erroneously attacking healthy tissues. Unfortunately, cancers have evolved to upregulate immune checkpoint molecules to evade immune detection and destruction. By obstructing these immunosuppressive signaling pathways with therapeutic drugs, immune checkpoint blockade strategies enable the formation of an optimal therapeutic antitumor immune response. Immune checkpoint blockade has led to unprecedented clinical success in patients with late-stage melanoma, non-small cell lung cancer, and bladder cancer. Numerous clinical trials are under way, and the Food and Drug Administration has already approved drugs targeting several immune checkpoint 
TABLE 1

Probes Targeted to Endogenous Immune Cell Biomarkers

\begin{tabular}{|c|c|c|c|c|c|c|}
\hline Target & Agent & Class & Reactivity & Modality & Stage & Study \\
\hline \multirow[t]{13}{*}{ PD-L1 } & ${ }^{18} \mathrm{~F}-\mathrm{BMS}-986192$ & Adnectin & Human/cynomolgus & PET & Preclinical & $(20)$ \\
\hline & 18F-NOTA-ZPDL1_1 & Affibody & Human/macaque & PET & Preclinical & $(21)$ \\
\hline & $\begin{array}{l}{ }^{64} \mathrm{Cu}-\mathrm{DOTA} \text {-HAC-PD1, }{ }^{64} \mathrm{Cu}-\mathrm{NOTA} \text {-HAC-PD1, } \\
{ }^{64} \mathrm{Cu}-\mathrm{NOTA} \text {-HACA-PD1, }{ }^{68} \mathrm{Ga}-\mathrm{NOTA} \text {-HAC-PD1, } \\
{ }^{68} \mathrm{Ga}-N O T A-H A C A-P D 1,{ }^{68} \mathrm{Ga}-D O T A-H A C A-P D 1\end{array}$ & HAC-PD1 & Human & PET & Preclinical & $(6,22)$ \\
\hline & $\begin{array}{l}{ }^{111} \text { In-atezolizumab, NIR-atezolizumab, } \\
{ }^{64} \mathrm{Cu} \text {-atezolizumab, }{ }^{89} \mathrm{Zr} \text {-atezolizumab }\end{array}$ & Humanized lgG1 & Human & SPECT, PET, optical & Clinical & $(23,24)$ \\
\hline & ${ }^{89} \mathrm{Zr}-\mathrm{C} 4$ & Humanized IgG1 & Human/murine & PET & Preclinical & (25) \\
\hline & ${ }^{111}$ In-PD-L1.3.1 & Murine lgG1 & Human & SPECT & Preclinical & $(10)$ \\
\hline & ${ }^{111}$ In-DTPA-anti-PDL1 & $\mathrm{mAb}$ & Murine & SPECT & Preclinical & $(26,27)$ \\
\hline & ${ }^{89} \mathrm{Zr}$-DFO-anti-PDL1 & $\mathrm{mAb}$ & Murine & PET & Preclinical & (28) \\
\hline & aPDL1-GNPs & Nanoparticle & Murine & CT & Preclinical & (29) \\
\hline & ${ }^{99 m T c-N b s}$ & Single-domain antibody & Murine & SPECT & Preclinical & $(30)$ \\
\hline & ${ }^{64} \mathrm{Cu}-\mathrm{WL} 12$ & Peptide & Human & PET & Preclinical & (31) \\
\hline & ${ }^{64} \mathrm{Cu}-\mathrm{NOTA}-\mathrm{PD}-\mathrm{L} 1$ & $\mathrm{mAb}$ & Murine & PET & Preclinical & $(32)$ \\
\hline & ${ }^{18} \mathrm{~F}-\mathrm{B} 3,{ }^{64} \mathrm{Cu}-\mathrm{B} 3$ & Camelid VHH & Murine & PET & Preclinical & (33) \\
\hline \multirow[t]{6}{*}{ PD-1 } & ${ }^{89} \mathrm{Zr}$-Df-pembrolizumab & Humanized IgG4 & Human & PET & Preclinical & $(34)$ \\
\hline & ${ }^{89} \mathrm{Zr}$-Df-nivolumab & Humanized IgG4 & Human & PET & Preclinical & $(35)$ \\
\hline & ${ }^{89} \mathrm{Zr}$-keytruda & Humanized lgG4 & Human & PET & Preclinical & $(36)$ \\
\hline & PD-1-liposome-DOX-64Cu/IRDye800CW & Rat lgG2a & Murine & NIRF/PET & Preclinical & $(37)$ \\
\hline & ${ }^{64} \mathrm{Cu}-\mathrm{NOTA}-\mathrm{PD}-1$ & $\mathrm{mAb}$ & Murine & PET & Preclinical & $(32)$ \\
\hline & ${ }^{64} \mathrm{Cu}-\mathrm{DOTA}$-anti-PD-1 & $\mathrm{mAb}$ & Murine & PET & Preclinical & $(38)$ \\
\hline \multirow[t]{2}{*}{ TCR } & ${ }^{89} \mathrm{Zr}$-Df-aTCRmu-F(ab')2 & $\mathrm{Fab}^{\prime} 2$ & Human & PET & Preclinical & $(39,40)$ \\
\hline & ${ }^{64} \mathrm{Cu}-\mathrm{DOT} A-\mathrm{KJ} 1-26$ & $\mathrm{mAb}$ & Murine & PET & Preclinical & $(41)$ \\
\hline \multirow[t]{2}{*}{$\mathrm{MHCl} / \mathrm{II}$} & ${ }^{18} \mathrm{~F}-\mathrm{VHH} 7,{ }^{18} \mathrm{~F}-\mathrm{VHHDC} 13$ & Camelid VHH & Murine & PET & Preclinical & $(42)$ \\
\hline & ${ }^{64} \mathrm{Cu}-\mathrm{VHH} 4$ & Camelid VHH & Human & PET & Preclinical & $(43)$ \\
\hline Granz B & ${ }^{68} \mathrm{Ga}-\mathrm{NOTA}-\mathrm{GZP}$ & Peptide & Murine & PET & Preclinical & $(44)$ \\
\hline \multirow[t]{2}{*}{ CTLA-4 } & ${ }^{64} \mathrm{Cu}-\mathrm{DOTA}$-anti-CTLA-4 & $\mathrm{mAb}$ & Murine & PET & Preclinical & $(44,57)$ \\
\hline & ${ }^{64} \mathrm{Cu}$-DOTA-ipilimumab & $\mathrm{mAb}$ & Human & PET & Preclinical & $(46)$ \\
\hline \multirow[t]{4}{*}{ CD8 } & ${ }^{89} \mathrm{Zr}-\mathrm{VHH}-\mathrm{X} 18$ & Camelid VHH & Murine & PET & Preclinical & (11) \\
\hline & ${ }^{89} \mathrm{Zr}$-malDFO-169cDb & Cys-diabody & Murine & PET & Preclinical & $(47)$ \\
\hline & ${ }^{64} \mathrm{Cu}-\mathrm{NOTA}-2.43 \mathrm{Mb}$ & Minibody & Murine & PET & Preclinical & $(48)$ \\
\hline & ${ }^{89} \mathrm{Zr}$-Df-IAB22M2C & Minibody & Human & PET & Clinical & $(48)$ \\
\hline CD4 & ${ }^{89} \mathrm{Zr}$-malDFO-GK1.5cDb & Cys-diabody & Murine & PET & Preclinical & $(50,51)$ \\
\hline CD3 & ${ }^{89} \mathrm{Zr}-\mathrm{DFO}-\mathrm{CD} 3$ & $\mathrm{mAb}$ & Murine & PET & Preclinical & $(52)$ \\
\hline \multirow[t]{2}{*}{ CD25 } & ${ }^{18} \mathrm{~F}-\mathrm{FB}-\mathrm{IL} 2$ & Wt IL2 & Murine & PET & Preclinical & (53) \\
\hline & 99mTc-IL2 & Wt IL2 & Human & SPECT & Clinical & $(54)$ \\
\hline \multirow[t]{7}{*}{ CD20 } & ${ }^{124} \mathrm{I}$-anti-CD20 scFv dimers & Diabody & Human & PET & Preclinical & $(55)$ \\
\hline & ${ }^{64} \mathrm{Cu}$-rituximab & $\mathrm{mAb}$ & Human & PET & Preclinical & $(17)$ \\
\hline & ${ }^{124} \mathrm{I}-\mathrm{GAcDb},{ }^{124} \mathrm{I}-\mathrm{GAcMb},{ }^{89} \mathrm{Zr}-\mathrm{GAcDb},{ }^{89} \mathrm{Zr}-\mathrm{GAcMb}$ & Cys-diabody, Cys-minibody & Human & PET & Preclinical & $(56)$ \\
\hline & ${ }^{64} \mathrm{Cu}-\mathrm{FN} 3 \mathrm{CD} 20$ & Fibronectin (FNIII) & Human & PET & Preclinical & $(57)$ \\
\hline & ${ }^{89} \mathrm{Zr}$-Df-Bz-rituximab & $\mathrm{mAb}$ & Human & PET & Preclinical & $(58,59)$ \\
\hline & ${ }^{89} \mathrm{Zr}$-anti-B220 & $\mathrm{mAb}$ & Murine & PET & Preclinical & $(60)$ \\
\hline & ${ }^{124} \mathrm{I}-\mathrm{scFV}-\mathrm{Fc}$ DM, ${ }^{124} \mathrm{I}-\mathrm{Mb},{ }^{64} \mathrm{Cu}-\mathrm{DOTA}-\mathrm{Mb}$ & Minibody, scFv & Human & PET & Preclinical & $(61)$ \\
\hline dCK & ${ }^{18} \mathrm{~F}-\mathrm{FAC},{ }^{18} \mathrm{~F}-\mathrm{CFA}$ & Small molecule & Murine/human & PET & Clinical & $(62,63)$ \\
\hline dGK & ${ }^{18} \mathrm{~F}-\mathrm{AraG}$ & Small molecule & Murine/human & PET & Clinical & $(16,64)$ \\
\hline TK1 & ${ }^{18} \mathrm{~F}-\mathrm{FLT}$ & Small molecule & Murine/human & PET & Clinical & (65) \\
\hline CD47 & ${ }^{89} \mathrm{Zr}$-anti-CD47-mAb & $\mathrm{mAb}$ & Murine/human & PET & Preclinical & $(66)$ \\
\hline CD276 & Anti-B7H3-microbubbles & Microbubble & Human & Ultrasound & Preclinical & $(67)$ \\
\hline CXCR4 & ${ }^{64} \mathrm{Cu}-\mathrm{AMD} 3100$ & $\mathrm{mAb}$ & Human & PET & Preclinical & (68) \\
\hline MMR & ${ }^{18} \mathrm{~F}-\mathrm{SFB}$ & Single-domain antibody & Murine & PET & Clinical & (69) \\
\hline OX40 & ${ }^{64} \mathrm{Cu}$-DOTA-OX40 & $\mathrm{mAb}$ & Murine & PET & Preclinical & $(70,71)$ \\
\hline
\end{tabular}

Common acronyms for modalities: $\mathrm{FLI}=$ fluorescence imaging; $\mathrm{BLI}=$ bioluminescence imaging; NIRF = near-infrared fluorescence imaging

Common acronyms for agents: $\mathrm{HAC}=$ high-affinity consensus; GNPs = gold nanoparticles; $\mathrm{Mb}=$ minibody; Nbs = single-domain antibodies; $\mathrm{cDb}=\mathrm{cys}$-diabody; $\mathrm{mAB}=$ monoclonal antibody; scFv = single-chain variable fragment; SPION = superparamagnetic iron oxide nanoparticle; CLIO = cross-linked iron oxide; GFP = green fluorescent protein; FLuc = firefly luciferase; NP = nanoparticle; FAC = fluoroarabinofuranosyl-cytosine; AraG = fluoroarabinofuranosyl-cytosine; dCK = deoxycytidine kinase; dGK = deoxyguanosine kinase; TK1 = thymidine kinase 1; FLT = fluorothymidine; FHBG = fluoro-3-hydroxymethylbutyl guanine; NIS = sodium iodide symporter. 
TABLE 2

Immune Cell Labeling Strategies

\begin{tabular}{|c|c|c|c|c|c|c|}
\hline Target & Agent & Class & Reactivity & Modality & Stage & Study \\
\hline \multirow[t]{15}{*}{ T cells } & ${ }^{64} \mathrm{Cu}$-PTSM & Small molecule & Murine/human & PET & Preclinical & (72) \\
\hline & ${ }^{18} \mathrm{~F}-\mathrm{FDG}$ & Small molecule & Murine/human & PET & Preclinical & (72) \\
\hline & 99mTc-MHPAO & Small molecule & Murine/human & SPECT & Preclinical & (72) \\
\hline & ${ }^{111}$ In-oxine & Small molecule & Murine/human & SPECT & Preclinical & (73) \\
\hline & CLIO-HD & Nanoparticle & Murine/human & MRI & Preclinical & (74) \\
\hline & ${ }^{124}$ I-FIAU & Reporter gene & Murine/human & PET & Clinical & (75) \\
\hline & ${ }^{18} \mathrm{~F}-\mathrm{FHBG}$ & Reporter gene & Murine/human & PET & Clinical & (13) \\
\hline & IOPC- $\mathrm{NH}_{2}$ & Nanoparticle & Murine/human & MRI & Preclinical & $(76)$ \\
\hline & PFPE/19F & Nanoparticle & Murine/human & $\mathrm{MRI}$ & Clinical & $(77)$ \\
\hline & ${ }^{64} \mathrm{Cu}-\mathrm{SPION}$ & Nanoparticle & Murine/human & PET & Preclinical & (78) \\
\hline & DiR fluorophore & Small molecule & Murine/human & FLI & Preclinical & (79) \\
\hline & $\begin{array}{l}\text { HSVI-sr39tk, HSV-tk, } \\
\text { HSV-tk-GFP }\end{array}$ & Reporter gene & Murine/human & PET/optical & Clinical & $(80)$ \\
\hline & Fluc & Reporter gene & Murine/human & $\mathrm{BLI}$ & Preclinical & $(81,82)$ \\
\hline & Sr39tk/ $/{ }^{18} \mathrm{~F}-\mathrm{FHBG}$ & Reporter gene & Murine/human & PET & Preclinical & (83) \\
\hline & ${ }^{18} \mathrm{~F}-\mathrm{FEAU}$ & Reporter gene & Murine/human & PET & Preclinical & (84) \\
\hline B cells & NIR nanoparticle & Nanoparticle & Murine/human & FLI & Preclinical & (85) \\
\hline Monocytes & ${ }^{18} \mathrm{~F}-\mathrm{FDG}$ & Small molecule & Murine/human & PET & Clinical & (6) \\
\hline \multirow[t]{9}{*}{ Macrophage } & NIR nanoparticle & Nanoparticle & Murine/human & FLI & Preclinical & $(87)$ \\
\hline & Ferumoxytol SPIO & Nanoparticle & Murine/human & MRI & Clinical & $(88,89)$ \\
\hline & Magnetic NP & Nanoparticle & Murine/human & MRI & Clinical & $(87)$ \\
\hline & Ferucarbotran & Nanoparticle & Murine/human & MRI & Clinical (discontinued) & $(90)$ \\
\hline & Ferumoxtran & Nanoparticle & Murine/human & MRI & Clinical (discontinued) & (91) \\
\hline & CLIO & Nanoparticle & Murine/human & MRI & Preclinical & (92) \\
\hline & ${ }^{89} \mathrm{Zr} /{ }^{64} \mathrm{Cu} /{ }^{18} \mathrm{~F}-\mathrm{DNP}$ & Nanoparticle & Murine & PET & Preclinical & (93) \\
\hline & Fluc & Reporter gene & Murine/human & BLI & Preclinical & $(94,95)$ \\
\hline & $\mathrm{NIS} /{ }^{124} \mathrm{I}$ & Reporter gene & Murine/human & PET & Clinical & $(94,96)$ \\
\hline \multirow[t]{13}{*}{ Dendritic cells } & ${ }^{111} \mathrm{In} /{ }^{99 m} \mathrm{Tc}-\mathrm{HMPAO}$ & Small molecule & Murine/human & SPECT & Clinical & $(97)$ \\
\hline & $111 \ln$ & Small molecule & Murine/human & SPECT & Clinical & $(98)$ \\
\hline & $\begin{array}{l}{ }^{19} \text { F-PFPE loaded with iron } \\
\text { particles }\end{array}$ & Nanoparticle & Murine/human & MRI & Preclinical & (99) \\
\hline & SPIO & Nanoparticle & Murine/human & MRI & Clinical & $(100)$ \\
\hline & NIR-QD & Quantum dot & Murine/human & FLI & Preclinical & $(101)$ \\
\hline & ${ }^{18} \mathrm{~F}-\mathrm{SFB}$ & Small molecule & Murine/human & PET & Clinical & $(102)$ \\
\hline & Ferumoxide & Nanoparticle & Murine/human & $\mathrm{MRI}$ & Clinical & (15) \\
\hline & Perfluorocarbon NP & Nanoparticle & Murine/human & MRI & Clinical & (103) \\
\hline & CFSE & Small molecule & Murine/human & $\mathrm{FLI}$ & Preclinical & $(104)$ \\
\hline & Fluc & Reporter gene & Murine/human & BLI & Preclinical & $(105)$ \\
\hline & $\mathrm{hNIS} /{ }^{124} \mathrm{I}$ & Reporter gene & Murine/human & PET & Clinical & $(105)$ \\
\hline & FTH & Reporter gene & Murine/human & MRI & Clinical & $(106)$ \\
\hline & GFP & Reporter gene & Murine/human & FLI & Preclinical & $(107)$ \\
\hline \multirow[t]{4}{*}{ NK cells } & Ferumoxides, ferucarbon & Nanoparticle & Murine/human & MRI & Preclinical & $(108)$ \\
\hline & NIR dye & Small molecule & Murine/human & FLI & Preclinical & $(109)$ \\
\hline & ${ }^{11} \mathrm{C}$ & Small molecule & Murine/human & PET & Clinical & $(110)$ \\
\hline & ${ }^{111} \ln$ & Small molecule & Murine/human & SPECT & Clinical & $(111)$ \\
\hline
\end{tabular}

Common acronyms for modalities: FLI = fluorescence imaging; $\mathrm{BLI}=$ bioluminescence imaging; NIRF = near-infrared fluorescence imaging.

Common acronyms for agents: HAC = high-affinity consensus; GNPs = gold nanoparticles; Mb = minibody; Nbs = single-domain antibodies; cDb = cys-diabody; $\mathrm{mAB}=$ monoclonal antibody; scFv = single-chain variable fragment; SPION = superparamagnetic iron oxide nanoparticle; CLIO = crosslinked iron oxide; GFP = green fluorescent protein; FLuc = firefly luciferase; NP = nanoparticle; FAC = fluoroarabinofuranosyl-cytosine; AraG = fluoroarabinofuranosyl-cytosine; dCK = deoxycytidine kinase; $d G K=$ deoxyguanosine kinase; TK1 = thymidine kinase 1; FLT = fluorothymidine; FHBG = fluoro-3hydroxymethylbutyl guanine; NIS = sodium iodide symporter. 
A Probes targeted for endogenous immune cell biomarkers

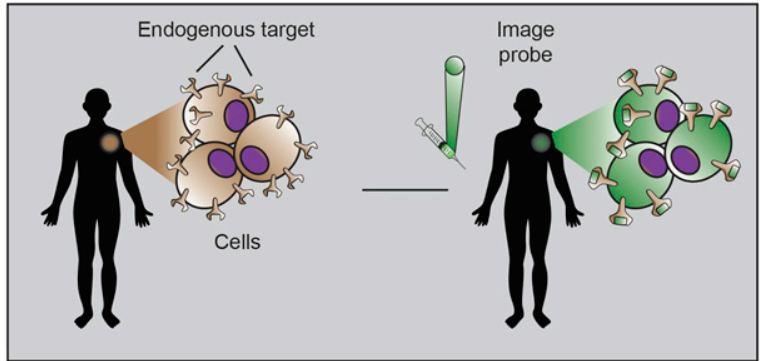

B

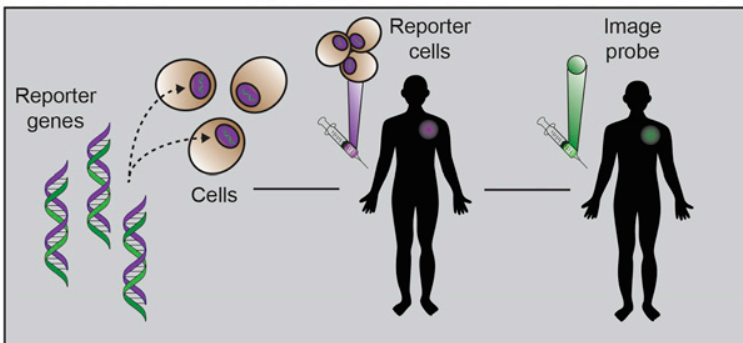

C Direct immune cell labeling strategies

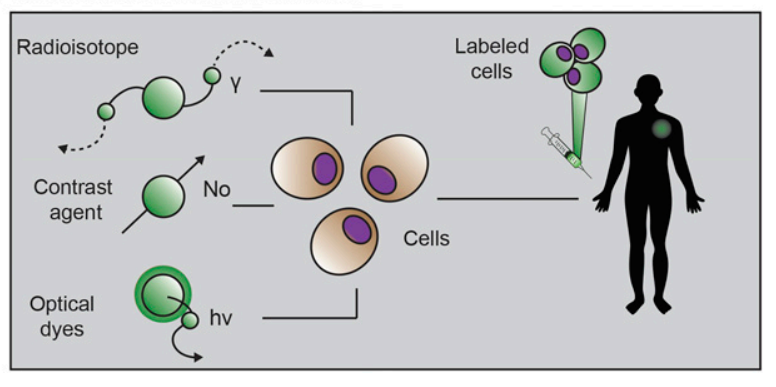

FIGURE 1. The 3 primary immunoimaging strategies. (A) Imaging probe targeting natural immune cell receptor is injected. (B) Cells from patient are transduced with reporter gene, reinjected, and visualized via injection of reporter probe. (C) Cells from patient are incubated ex vivo with imaging probe, and labeled cells are injected into patient and monitored via imaging. (Adapted from Kurtz et al. (112).)

molecules: cytotoxic T-lymphocyte antigen-4 (CTLA-4), programmed death-1 (PD-1), and programmed death ligand-1 (PD-L1) (9). Despite the success of immune checkpoint blockade, only a subset of patients responds.

Several tools are being developed in hopes of predicting which patients are most likely to respond to immune checkpoint blockade therapy. Probes targeting endogenous immune cell biomarkers are particularly well suited for measuring the dynamic and heterogeneous expression of immune checkpoint molecules. Numerous imaging agents have been developed and applied in an attempt to noninvasively interrogate PD-1, PD-L1, and CTLA-4 expression. For example, Heskamp et al. demonstrated the successful development of a monoclonal antibody labeled with ${ }^{111}$ In for SPECT/CT imaging of human PD-L1 expression in mice (10). Their mouse images showed heterogeneous uptake that correlated well with PD-L1 expression in multiple types of human tumor xenografts. They concluded that the technique may enable better patient selection for future therapy targeted at PD-1 and PD-L1. In addition to the expression of immune checkpoint molecules, the presence of immune cells before or after immune checkpoint blockade therapy may correlate with therapeutic response.
A Immune checkpoint blockade

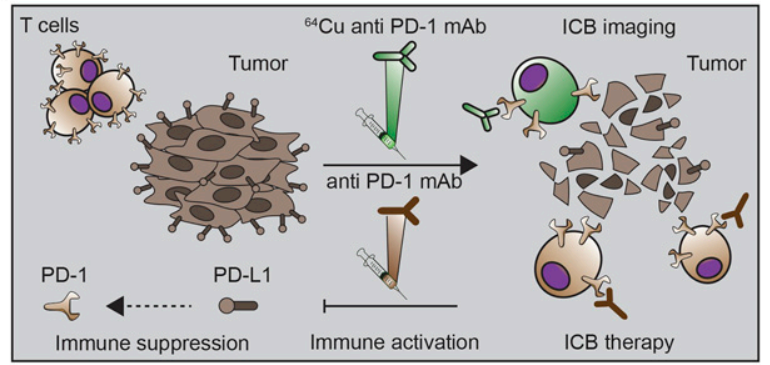

B

Chimeric antigen receptor $\mathrm{T}$ cell therapy

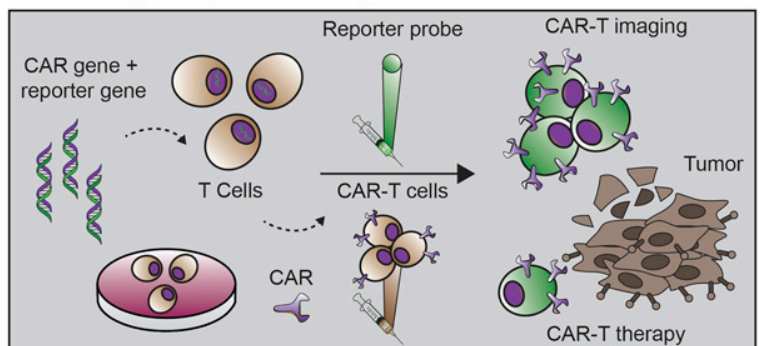

C

Dendritic cell vaccines

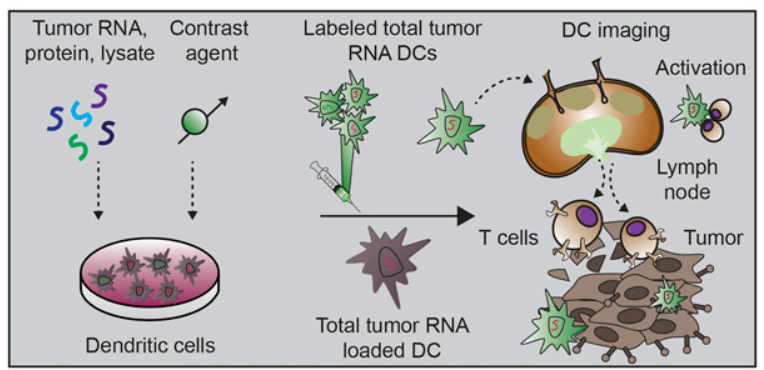

FIGURE 2. The 3 important classes of cancer immunotherapy. (A) Immune checkpoints that regulate antitumor immunity have now been identified as promising therapeutic targets. Blocking of signaling pathways that suppress antitumor immune response has proven especially effective. In one approach, anti-PD-1 mAb targets $\mathrm{PD}-1$ receptor on $\mathrm{T}$ cells, blocking ligation of receptor and immunosuppression by PD-L1 on tumor cells. Anti-PD1 mAb administration thus leads to immune activation and therapeutic response. Imaging of PD1 expression with radiolabeled mAb may assist in selection of patients for treatment, optimal dosing, and response monitoring. (B) CAR-T strategies engineer patient's immune cells ex vivo to express receptor that can bind specifically to tumor cells. During this engineering process, reporter gene can also be inserted to enable longitudinal tracking of CAR-Ts. On administration, CAR-Ts seek out and destroy malignant tumor cells. Subsequent imaging with reporter probe can give insight into their location and functional status. (C) Cancer vaccine strategies come in many formulations. In one approach, dendritic cells are pulsed with tumor antigen, lysate, or RNA. Dendritic cells then express tumor antigens on their major-histocompatibility-complex molecules, which are capable of eliciting Tcell-driven immune response. Successful responses require homing of dendritic cells to lymph nodes and tumor. At these sites, dendritic cells can activate tumor-specific $\mathrm{T}$ cells. Labeling of dendritic cells with contrast agent allows for assessment of successful homing of dendritic cells to lymph nodes and other secondary lymphoid sites. This knowledge can be used to inform both dose and route of vaccine administration.

Rashidian et al. showed that ${ }^{89} \mathrm{Zr}$-labeled PEGylated single-domain antibody fragments (VHHs [the variable region of a heavy chain of a camelid antibody]) specific for CD8 enable immunoPET tracking of cytotoxic T cells (11). Although the absolute 

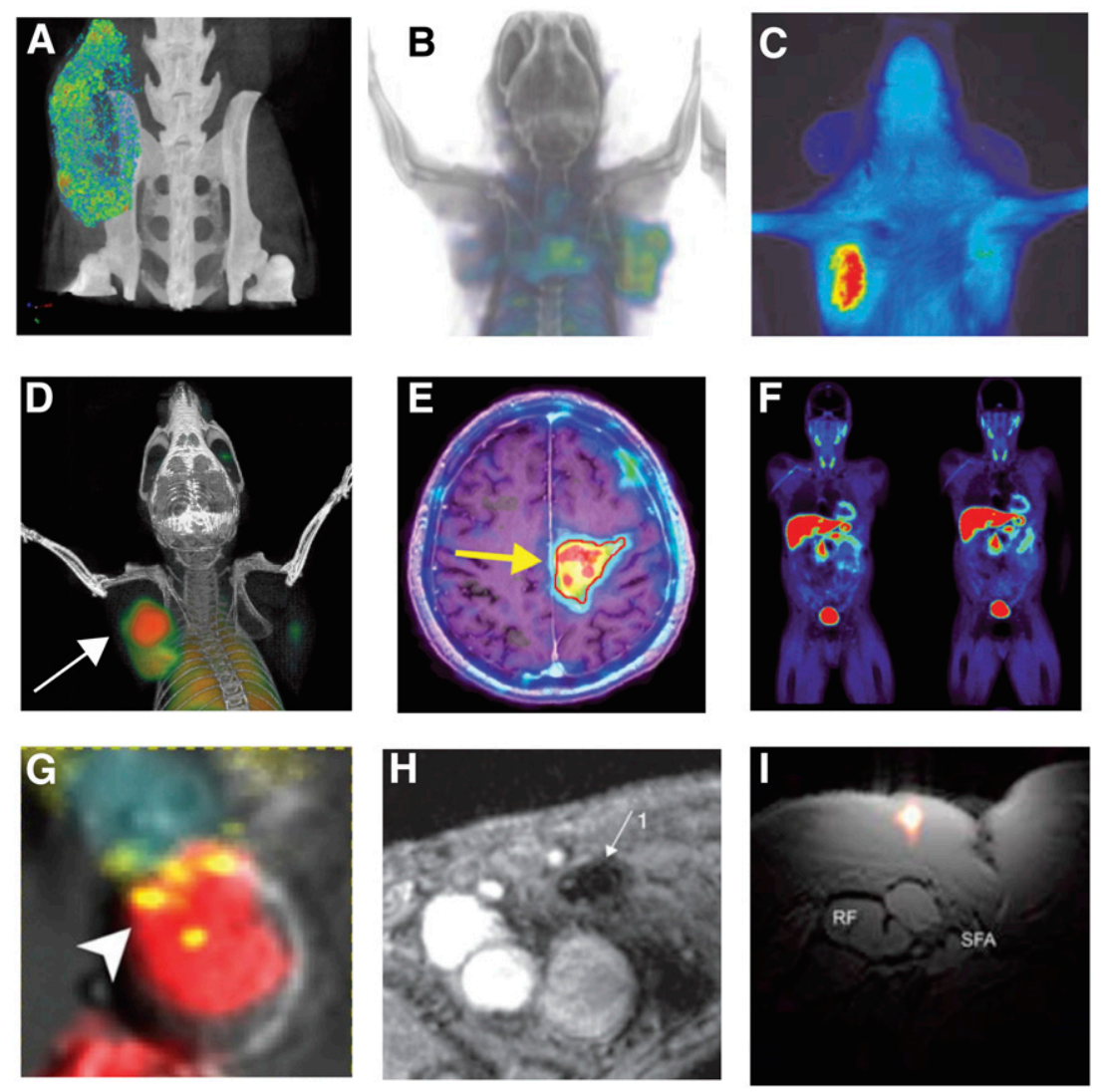

FIGURE 3. Immunoimaging examples. (A-C) Imaging of PD-L1 immune checkpoint: CT using anti-PD-L1 gold nanoparticles (adapted from Meir et al. (30)) (A); PET (B) and optical imaging (C) of humanized antibody to assess PD-L1 expression in tumors (adapted from Chatterjee et al. (113)). (D-F) Imaging of activated T cells: PET of OX40 expressed on activated T cells after vaccine treatment within tumor (arrow) (adapted from Alam et al. (70,71)) (D); reporter gene imaging of targeted T-cell immunotherapy in recurrent glioma (arrow) (adapted from Keu et al. (13)) (E); PET of ${ }^{18} \mathrm{~F}$-AraG to visualize activated T cells in acute graft-vs.-host disease (adapted from Ronald et al. (16)) (F). (G-I) Imaging of myeloid cells: optical imaging revealing tumor-associated macrophagemediated mechanism of resistance to anti-PD1 therapy (adapted from Arlauckas et al. (114); macrophage is in red, T cell in blue, and PD-1 in yellow) (G); MRI of dendritic cells labeled with superparamagnetic iron oxide (adapted from de Vries et al. (15); arrow indicates site of decreased signal in lymph node due to superparamagnetic iron oxide-labeled dendritic cell accumulation) $(H)$; axial composite ${ }^{19} \mathrm{~F} /{ }^{1} \mathrm{H}$ MRI after intradermal dendritic cell administration into quadriceps of patient (adapted from Ahrens et al. (103); RF = rectus femoris; SFA = superficial femoral artery) (I).

number of intratumoral CD8 T cells measured by PET imaging did not correlate well with therapeutic response to CTLA-4 checkpoint blockade, the distribution of $\mathrm{T}$ cells in the tumor did. Homogeneous uptake patterns, indicative of good T-cell penetration and tumor coverage, stratified responders from nonresponders in this study. It is likely that both immune checkpoint expression and immune cell intratumoral distribution will provide valuable insight into clinical responses to immune checkpoint blockade therapy.

\section{Chimeric Antigen Receptor T Cells (CAR-Ts)}

CAR-Ts represent a personalized therapeutic approach in which $\mathrm{T}$ cells are removed from a patient and genetically engineered to express a chimeric antigen receptor before being introduced back into the patient. Chimeric antigen receptors have been designed to bind a variety of tumor-associated antigens. Newer generations of CAR-Ts have coupled these extracellular binding domains to intracellular costimulatory moieties, improving therapeutic potency and efficacy. Thus far, CAR-T strategies have seen the greatest success in treating hematologic malignancies, whereas they have struggled to find efficacy in solid tumors. In addition, CAR-T therapies often present with severe side effects, including cytokine release syndrome, neurologic toxic effects, and, in some cases, even death (12). "On-target, off-tumor" toxicity is another common concern. For example, CAR-Ts targeting CD19 will eradicate not only malignant CD19-positive B cells but also normal CD19-positive B cells, leading to B-cell aplasia. Despite durable remissions in certain patients, approximately half will exhibit relapse. The reasons for variations in patient response are not yet well understood, though they are likely linked to CAR-T durability, antigen loss, and on-target, off-tumor effects.

Reporter gene imaging strategies lend themselves readily to CAR-T therapy, as the cells already need to be removed from the patient and genetically engineered. Keu et al. recently demonstrated reporter gene imaging of CAR-Ts in glioblastoma patients $(13,14)$. In this study, cytotoxic $\mathrm{T}$ cells bearing the chimeric antigen receptor interleukin-13 zetakine for interleukin-13 receptor $\alpha$-positive tumor targeting were engineered to also express HSV1-tk as a dual-purpose suicide and imaging reporter gene. ${ }^{18}$ F-fluoro-3-hydroxymethylbutyl guanine PET imaging was subsequently used to longitudinally monitor CAR-T trafficking, survival, and proliferation in multiple patients with recurrent high-grade glioma. Although this study faced many challenges, including strict Food and Drug Administration regulations limiting the number of scans and access to patients, it provides a proof of principle that reporter gene imaging may one day be able to link cytotoxic T-lymphocyte trafficking and viability to tumor response and patient survival, guiding both the development and the application of CAR therapy for the treatment of solid tumors.

\section{Dendritic Cell Vaccines}

Dendritic cell vaccines comprise a special class of immunotherapy in which professional antigen-presenting cells, known as dendritic cells, are loaded ex vivo with an antigen and then adoptively transferred back to the patient. When successful, the antigen-loaded dendritic cells lead to the generation of an adaptive immune response against the target antigen of interest. For these therapies to be effective, though, the dendritic cells must migrate through the lymphatic system to lymph nodes where they can present the antigen and activate effector immune cells. Successful homing to secondary lymphoid organs represents an intermediate endpoint that might be used to improve or predict the success of dendritic cell vaccine strategies. 
Direct cell labeling and imaging are well suited toward elucidating the ideal route of administration and the fate of dendritic cells after injection. Many direct cell-labeling approaches using MRI have been attempted for monitoring dendritic cell vaccines for immunotherapy. MRI tracking of dendritic cells using superparamagnetic iron oxide nanoparticles has recently been tested in the clinic. In one such study, superparamagnetic iron oxide-labeled dendritic cells were injected intranodally into patients bearing melanoma (15). MRI was able to detect lymph nodes containing labeled dendritic cells with high sensitivity and revealed several patients who had been misinjected during therapy. In this case, it is clear how imaging might help potentially improve therapeutic success rates in patients receiving dendritic cell vaccines.

Applications of immunoimaging go far beyond the several highlighted here. In the coming years, there will likely be increasing applications of the immunoimaging toolbox toward autoimmune diseases such as graft-versus-host disease (10) and rheumatoid arthritis, as well as neurodegenerative diseases with an immune component such as multiple sclerosis (17) and Alzheimer disease.

\section{THE EXPANDING ROLES FOR IMMUNOIMAGING}

For immunotherapies to succeed, they must make it from the bench to the bedside, with the lessons learned being brought back to the bench. The standard drug development pipeline usually consists of target identification and assessment, lead compound optimization, preclinical studies, clinical phases I-III, and, finally, Food and Drug Administration approval. This pipeline represents an approximately 15 -y effort costing hundreds of millions of dollars, with 1 in 10,000 compounds ultimately achieving success (18).

Immunoimaging has several roles to play in the immunotherapy drug development pipeline and might help streamline clinical translation of immunotherapy strategies. During preclinical assessment of cancer immunotherapies, imaging can help guide rational therapy optimization. Compared with many preclinical drug studies in which survival is the primary endpoint, immunoimaging can give specific insight into the therapeutic mechanisms of action and failure. As we have seen in the examples provided in this review, imaging can elucidate whether immune cells are sufficiently homing to the disease site, whether they are activated on arrival, and how long they viably persist. With this information, one can tailor the treatment to overcome specific therapeutic obstacles rather than taking a random combinatorial approach toward therapeutic optimization. As drugs progress from a company's preclinical pipeline into clinical trials, immunoimaging has the potential to enable better patient selection and stratification to improve trial design and, hopefully, outcomes. With the increase in personalized-medicine approaches and highly targeted therapeutics (i.e., checkpoint inhibitors), it is critical to see whether the patient expresses the drug target before the drug is administered. Target expression is difficult to capture using any technique besides imaging because of highly heterogeneous expression and spatiotemporal variance. PET imaging lends itself readily to this challenge and can even enable quantitative assessment of target expression, informing not only patient and drug selection but drug dosing as well. Finally, once a drug has received Food and Drug Administration approval, immunoimaging can serve as a companion diagnostic and monitoring tool for improved patient management. Dynamic changes in immune cell response and checkpoint expression might inform when to switch a patient from one drug to another, or whether the patient is responding and no longer needs to receive costly therapy. In this way, imaging will enable physicians to make better decisions on treatment options and patient follow-up.

For new immunoimaging techniques to be adopted and succeed in the clinic, the field needs to move toward demonstrating the potential utility of novel probes or biomarkers during preclinical studies. Too often, a study concludes with simply validating an immunoimaging probe as being specific and sensitive. Future studies will need to show that immunoimaging agents give novel or actionable insight into immune response and therapy. Comparative analyses of immunoimaging agents being proposed for similar purposes need to be done, and mathematic modeling should be increasingly performed to derive guiding principles for immunoimaging design and application. The burden still lies on many novel imaging probes to show that they add information to anatomic scans or the commonly used ${ }^{18}$ F-FDG PET (19). Efforts invested in translating the most promising immunoimaging agents need to be accelerated to keep pace with the pace of drug development. Finally, immunoimaging should not be thought of as a competing tool with blood-based biomarkers or "omic" approaches. It is our belief that true success toward understanding and predicting response to immunotherapy will rely on the integration of the immunoimaging toolbox with both omics and systems immunology tools. Machine learning and artificial intelligence will be necessary to make sense of the highly dimensional datasets acquired across multiple modalities, and these systems will ultimately lead to better clinical decision making and improved patient outcomes. It is clear that the immunoimaging toolbox will continue to expand, and novel imaging strategies will likely play an increasing role in the clinic in years to come.

\section{DISCLOSURE}

Funding support was provided by the Canary Foundation, the Ben \& Catherine Ivy Foundation, the Sir Peter Michael Foundation, the Parker Foundation, and the NCI (grant R01 CA201719 to Sanjiv Gambhir). Dr. Gambhir is the founder of CellSight Technologies, which commercializes strategies for imaging immunotherapies. No other potential conflict of interest relevant to this article was reported.

\section{ACKNOWLEDGMENTS}

We thank the numerous trainees over the last 20 years in the Gambhir Lab who helped make possible several of the strategies discussed in this review.

\section{REFERENCES}

1. Slomka PJ, Pan T, Germano G. Recent advances and future progress in PET instrumentation. Semin Nucl Med. 2016;46:5-19.

2. De Groeve K, Deschacht N, De Koninck C, et al. Nanobodies as tools for in vivo imaging of specific immune cell types. J Nucl Med. 2010;51:782-789.

3. Ngen EJ, Artemov D. Advances in monitoring cell-based therapies with magnetic resonance imaging: future perspectives. Int J Mol Sci. 2017;18:14-22.

4. Liao F, Xu H, Torrey N, Road P, Jolla L. In vivo imaging with antibodies and engineered fragments. 2015;2:142-152.

5. Vaneycken I, D'huyvetter M, Hernot S, et al. Immuno-imaging using nanobodies. Curr Opin Biotechnol. 2011;22:877-881.

6. Maute RL, Gordon SR, Mayer AT, et al. Engineering high-affinity PD-1 variants for optimized immunotherapy and immuno-PET imaging. Proc Natl Acad Sci USA. 2015;112:E6506-E6514.

7. Wittrup KD, Thurber GM, Schmidt MM, et al. Practical theoretic guidance for the design of tumor-targeting agents. Methods Enzymol. 2012;503:255-268. 
8. Brader P, Serganova I, Blasberg RG. Noninvasive molecular imaging using reporter genes. $J$ Nucl Med. 2013;54:167-172.

9. Ehlerding EB, England CG, McNeel DG, Cai W. Molecular imaging of immunotherapy targets in cancer. $J$ Nucl Med. 2016;57:1487-1492.

10. Heskamp S, Hobo W, Molkenboer-Kuenen JD, et al. Non-invasive imaging of tumor PD-L1 expression using radiolabeled anti-PD-L1 antibodies. Cancer Res. 2015;75:2928-2936.

11. Rashidian M, Ingram JR, Dougan M, et al. Predicting the response to CTLA-4 blockade by longitudinal noninvasive monitoring of CD8 T cells. J Exp Med. 2017;214:2243-2255.

12. Bonifant CL, Jackson HJ, Brentjens RJ, Curran KJ. Toxicity and management in CAR T-cell therapy. Mol Ther Oncolytics. 2016;3:16011.

13. Keu KV, Witney TH, Yaghoubi S, et al. Reporter gene imaging of targeted T cell immunotherapy in recurrent glioma. Sci Transl Med. 2017;9:eaag2196.

14. Yaghoubi SS, Jensen MC, Satyamurthy N, et al. Noninvasive detection of therapeutic cytolytic $\mathrm{T}$ cells with ${ }^{18} \mathrm{~F}$-FHBG PET in a patient with glioma. Nat Clin Pract Oncol. 2009;6:53-58.

15. de Vries IJM, Lesterhuis WJ, Barentsz JO, et al. Magnetic resonance tracking of dendritic cells in melanoma patients for monitoring of cellular therapy. Nat Biotechnol. 2005;23:1407-1413.

16. Ronald JA, Kim BS, Gowrishankar G, et al. A PET imaging strategy to visualize activated $\mathrm{T}$ cells in acute graft-versus-host disease elicited by allogenic hematopoietic cell transplant. Cancer Res. 2017;77:2893-2902.

17. James ML, Hoehne A, Mayer AT, et al. Imaging B cells in a mouse model of multiple sclerosis using ${ }^{64} \mathrm{Cu}$-rituximab-PET. J Nucl Med. 2017;58:1845-1851.

18. Willmann JK, van Bruggen N, Dinkelborg LM, Gambhir SS. Molecular imaging in drug development. Nat Rev Drug Discov. 2008;7:591-607.

19. Cho SY, Lipson EJ, Im HJ, et al. Prediction of response to immune checkpoint inhibitor therapy using early time-point FDG-PET/CT imaging in patients with advanced melanoma. J Nucl Med. 2017;58:1421-1428.

20. Donnelly DJ, Smith RA, Morin P, et al. Synthesis and biological evaluation of a novel ${ }^{18} \mathrm{~F}$-labeled adnectin as a PET radioligand for imaging PD-L1 expression. J Nucl Med. 2018;59:529-535.

21. González Trotter DE, Meng X, McQuade P, et al. In vivo imaging of the programmed death ligand 1 by ${ }^{18} \mathrm{~F}$ positron emission tomography. J Nucl Med. 2017;58:1852-1857.

22. Mayer AT, Natarajan A, Gordon S, et al. Practical immunoPET radiotracer design considerations for human immune checkpoint imaging. J Nucl Med. 2017;58:538-546.

23. Chatterjee S, Lesniak WG, Nimmagadda S. Noninvasive imaging of immune checkpoint ligand PD-L1 in tumors and metastases for guiding immunotherapy. Mol Imaging. 2017;16:1536012117718459.

24. Lesniak WG, Chatterjee S, Gabrielson M, et al. PD-L1 detection in tumors using $\left[{ }^{64} \mathrm{Cu}\right]$ atezolizumab with PET. Bioconjug Chem. 2016;27:2103-2110.

25. Truillet C, Oh HLJ, Yeo SP, et al. Imaging PD-L1 expression with immunoPET. Bioconjug Chem. 2018;29:96-103.

26. Josefsson A, Nedrow JR, Park S, et al. Imaging, biodistribution, and dosimetry of radionuclide-labeled PD-L1 antibody in an immunocompetent mouse model of breast cancer. Cancer Res. 2016;76:472-479.

27. Nedrow JR, Josefsson A, Park S, et al. Imaging of programmed cell death ligand 1: impact of protein concentration on distribution of anti-PD-L1 SPECT agents in an immunocompetent murine model of melanoma. J Nucl Med. 2017;58:1560-1566.

28. Kikuchi M, Clump DA, Srivastava RM, et al. Preclinical immunoPET/CT imaging using Zr-89-labeled anti-PD-L1 monoclonal antibody for assessing radiation-induced PD-L1 upregulation in head and neck cancer and melanoma. Oncoimmunology. 2017;6:e1329071.

29. Meir R, Shamalov K, Sadan T, et al. Fast image-guided stratification using antiprogrammed death ligand 1 gold nanoparticles for cancer immunotherapy. ACS Nano. 2017;11:11127-11134.

30. Broos K, Keyaerts M, Lecocq Q, et al. Non-invasive assessment of murine PDL1 levels in syngeneic tumor models by nuclear imaging with nanobody tracers. Oncotarget. 2017;8:41932-41946.

31. Chatterjee S, Lesniak WG, Miller MS, et al. Rapid PD-L1 detection in tumors with PET using a highly specific peptide. Biochem Biophys Res Commun. 2017;483:258-263.

32. Hettich M, Braun F, Bartholomä MD, Schirmbeck R, Niedermann G. Highresolution PET imaging with therapeutic antibody-based PD-1/PD-L1 checkpoint tracers. Theranostics. 2016;6:1629-1640.

33. Ingram JR, Dougan M, Rashidian M, et al. PD-L1 is an activation-independent marker of brown adipocytes. Nat Commun. 2017;8:647.

34. England CG, Ehlerding EB, Hernandez R, et al. Preclinical pharmacokinetics and biodistribution studies of ${ }^{89} \mathrm{Zr}$-labeled pembrolizumab. J Nucl Med. 2016;58:162-168.

35. England CG, Jiang D, Ehlerding EB, et al. ${ }^{89} \mathrm{Zr}$-labeled nivolumab for imaging of T-cell infiltration in a humanized murine model of lung cancer. Eur J Nucl Med Mol Imaging. 2018;45:110-120.
36. Natarajan A, Mayer AT, Reeves RE, Nagamine CM, Gambhir SS. Development of novel immunoPET tracers to image human PD-1 checkpoint expression on tumor-infiltrating lymphocytes in a humanized mouse model. Mol Imaging Biol. 2017;19:903-914.

37. Du Y, Liang X, Li Y, et al. Nuclear and fluorescent labeled PD-1-liposomeDOX- ${ }^{64} \mathrm{Cu} / \mathrm{IRDye} 800 \mathrm{CW}$ allows improved breast tumor targeted imaging and therapy. Mol Pharm. 2017;14:3978-3986.

38. Natarajan A, Mayer AT, Xu L, et al. A novel radiotracer for immunoPET imaging of PD-1 checkpoint expression on tumor infiltrating lymphocytes. Bioconjug Chem. 2015;26:2062-2069.

39. Yusufi N, Mall S, Bianchi HO, et al. In-depth characterization of a TCR-specific tracer for sensitive detection of tumor-directed transgenic $\mathrm{T}$ cells by immunoPET. Theranostics. 2017;7:2402-2416.

40. Mall S, Yusufi N, Wagner R, et al. Immuno-PET imaging of engineered human T cells in tumors. Cancer Res. 2016;76:4113-4123.

41. Griessinger CM, Maurer A, Kesenheimer C, et al. ${ }^{64} \mathrm{Cu}$ antibody-targeting of the T-cell receptor and subsequent internalization enables in vivo tracking of lymphocytes by PET. Proc Natl Acad Sci USA. 2015;112:1161-1166.

42. Rashidian M, Keliher EJ, Bilate AM, et al. Noninvasive imaging of immune responses. Proc Natl Acad Sci USA. 2015;112:6146-6151.

43. Van Elssen $\mathrm{CH}$, Rashidian M, Vrbanac V, et al. Noninvasive imaging of human immune responses in a human xenograft model of graft-versus-host disease. J Nucl Med. 2017;58:1003-1008.

44. Larimer BM, Wehrenberg-Klee E, Dubois F, et al. Granzyme B PET imaging as a predictive biomarker of immunotherapy response. Cancer Res. 2017;77:2318-2327.

45. Higashikawa $\mathrm{K}$, Yagi $\mathrm{K}$, Watanabe $\mathrm{K}$, et al. ${ }^{64} \mathrm{Cu}$-DOTA-anti-CTLA-4 mAb enabled PET visualization of CTLA-4 on the T-cell infiltrating tumor tissues. PLoS One. 2014;9:e109866.

46. Ehlerding EB, England CG, Majewski RL, et al. ImmunoPET imaging of CTLA-4 expression in mouse models of non-small cell lung cancer. $\mathrm{Mol}$ Pharm. 2017;14:1782-1789.

47. Tavaré R, Escuin-Ordinas H, Mok S, et al. An effective immuno-PET imaging method to monitor CD8-dependent responses to immunotherapy. Cancer Res. 2016;76:73-82.

48. Tavaré R, McCracken MN, Zettlitz KA, et al. Engineered antibody fragments for immuno-PET imaging of endogenous CD8 + T cells in vivo. Proc Natl Acad Sci USA. 2014;111:1108-1113.

49. Olafsen T, Torgov M, Zhang GG, et al. Pet imaging of cytotoxic human T cells using an ${ }^{89} \mathrm{Zr}$-labeled anti-CD8 minibody [abstract]. J Immunother Cancer. 2015;3(suppl 2):P388.

50. Tavaré R, McCracken MN, Zettlitz KA, et al. Immuno-PET of murine T cell reconstitution postadoptive stem cell transplantation using anti-CD4 and antiCD8 cys-diabodies. J Nucl Med. 2015;56:1258-1264.

51. Freise AC, Zettlitz KA, Salazar FB, et al. ImmunoPET imaging of murine CD4+ $\mathrm{T}$ cells using anti-CD4 cys-diabody: effects of protein dose on $\mathrm{T}$ cell function and imaging. Mol Imaging Biol. 2017;19:599-609.

52. Larimer BM, Wehrenberg-Klee E, Caraballo A, Mahmood U. Quantitative CD3 PET imaging predicts tumor growth response to anti-CTLA-4 therapy. $J$ Nucl Med. 2016;57:1607-1611.

53. Hartimath SV, Draghiciu O, van de Wall S, et al. Noninvasive monitoring of cancer therapy induced activated $\mathrm{T}$ cells using $\left[{ }^{18} \mathrm{~F}\right] \mathrm{FB}-\mathrm{IL}-2$ PET imaging. Oncoimmunology. 2016;6:e1248014.

54. Glaudemans AWJM, Bonanno E, Galli F, et al. In vivo and in vitro evidence that ${ }^{99 m}$ Tc-HYNIC-interleukin-2 is able to detect T lymphocytes in vulnerable atherosclerotic plaques of the carotid artery. Eur J Nucl Med Mol Imaging. 2014;41:1710-1719.

55. Olafsen T, Sirk SJ, Betting DJ, et al. ImmunoPET imaging of B-cell lymphoma using ${ }^{124} \mathrm{I}$-anti-CD20 scFv dimers (diabodies). Protein Eng Des Sel. 2010;23:243-249.

56. Zettlitz KA, Tavare R, Knowles SM, et al. ImmunoPET of malignant and normal B cells with ${ }^{89} \mathrm{Zr}$ - and ${ }^{124} \mathrm{I}$-labeled obinutuzumab antibody fragments reveals differential CD20 internalization in vivo. Clin Cancer Res. 2017;23:7242-7252.

57. Natarajan A, Hackel BJ, Gambhir SS. A novel engineered anti-CD20 tracer enables early time PET imaging in a humanized transgenic mouse model of Bcell non-Hodgkin's lymphoma. Clin Cancer Res. 2013;19:6820-6829.

58. Natarajan A, Habte F, Gambhir SS. Development of a novel long-lived immunoPET tracer for monitoring lymphoma therapy in a humanized transgenic mouse model. Bioconjug Chem. 2012;23:1221-1229.

59. Natarajan A, Gambhir SS. Radiation dosimetry study of $\left[{ }^{89} \mathrm{Zr}\right]$ rituximab tracer for clinical translation of B cell NHL imaging using positron emission tomography. Mol Imaging Biol. 2015;17:539-547.

60. Walther M, Gebhardt P, Grosse-Gehling P, et al. Implementation of ${ }^{89} \mathrm{Zr}$ production and in vivo imaging of B-cells in mice with ${ }^{89} \mathrm{Zr}$-labeled anti-B-cell antibodies by small animal PET/CT. Appl Radiat Isot. 2011;69:852-857. 
61. Olafsen T, Betting D, Kenanova VE, et al. Recombinant anti-CD20 antibody fragments for small-animal PET imaging of B-cell lymphomas. J Nucl Med. 2009;50:1500-1508.

62. Radu CG, Shu CJ, Nair-Gill E, et al. Molecular imaging of lymphoid organs and immune activation by positron emission tomography with a new $\left[{ }^{18} \mathrm{~F}\right]-$ labeled 2-deoxycytidine analog. Nat Med. 2008;14:783-788.

63. Kim W, Le TM, Wei L, et al. $\left[{ }^{18} \mathrm{~F}\right] \mathrm{CFA}$ as a clinically translatable probe for PET imaging of deoxycytidine kinase activity. Proc Natl Acad Sci USA. 2016;113:4027-4032.

64. Namavari M, Chang YF, Kusler B, et al. Synthesis of $2^{\prime}$-deoxy- $2^{\prime}-\left[{ }^{18}\right.$ F $]$ fluoro9-D-arabinofuranosylguanine: a novel agent for imaging T-cell activation with PET. Mol Imaging Biol. 2011;13:812-818.

65. Ribas A, Benz MR, Allen-Auerbach MS, et al. Imaging of CTLA4 blockadeinduced cell replication with ${ }^{18} \mathrm{~F}$-FLT PET in patients with advanced melanoma treated with tremelimumab. J Nucl Med. 2010;51:340-346.

66. Zheleznyak A, Ikotun OF, Dimitry J, Frazier WA, Lapi SE. Imaging of CD47 expression in xenograft and allograft tumor models. Mol Imaging. 2013;12:1-10.

67. Bachawal SV, Jensen KC, Wilson KE, et al. Breast cancer detection by B7-H3targeted ultrasound molecular imaging. Cancer Res. 2015;75:2501-2509.

68. Nimmagadda S, Pullambhatla M, Stone K, et al. Molecular imaging of CXCR4 receptor expression in human cancer xenografts with $\left[{ }^{64} \mathrm{Cu}\right] \mathrm{AMD} 3100$ positron emission tomography. Cancer Res. 2010;70:3935-3944.

69. Blykers A, Schoonooghe S, Xavier C, et al. PET imaging of macrophage mannose receptor-expressing macrophages in tumor stroma using ${ }^{18} \mathrm{~F}$-radiolabeled camelid single-domain antibody fragments. J Nucl Med. 2015;56:1265-1271.

70. Sagiv-Barfi I, Czerwinski DK, Levy S, et al. Eradication of spontaneous malignancy by local immunotherapy. Sci Transl Med. 2018;10:eaan4488.

71. Alam IS, Mayer AT, Sagiv-Barfi I, et al. Imaging activated T cells predicts response to cancer vaccines. J Clin Invest. 2018(May 14):98509.

72. Botti C, Negri DRM, Seregni E, et al. Comparison of three different methods for radiolabelling human activated T lymphocytes. Eur J Nucl Med. 1997;24:497-504.

73. Pittet MJ, Grimm J, Berger CR, et al. In vivo imaging of T cell delivery to tumors after adoptive transfer therapy. Proc Natl Acad Sci USA. 2007;104:12457-12461.

74. Kircher MF, Allport JR, Graves EE, et al. In vivo high resolution three-dimensional imaging of antigen-specific cytotoxic T-lymphocyte trafficking to tumors. Cancer Res. 2003;63:6838-6846.

75. Zanzonico P, Koehne G, Gallardo HF, et al. $\left[{ }^{131} \mathrm{I}\right] \mathrm{FIAU}$ labeling of genetically transduced, tumor-reactive lymphocytes: cell-level dosimetry and dose-dependent toxicity. Eur J Nucl Med Mol Imaging. 2006;33:988-997.

76. Liu L, Ye Q, Wu Y, et al. Tracking T-cells in vivo with a new nano-sized MRI contrast agent. Nanomedicine. 2012;8:1345-1354.

77. Srinivas M, Morel PA, Ernst LA, Laidlaw DH, Ahrens ET. Fluorine-19 MRI for visualization and quantification of cell migration in a diabetes model. Magn Reson Med. 2007;58:725-734.

78. Bhatnagar P, Alauddin M, Bankson JA, et al. Tumor lysing genetically engineered T cells loaded with multi-modal imaging agents. Sci Rep. 2014;4:4502.

79. Youniss FM, Sundaresan G, Graham LJ, et al. Near-infrared imaging of adoptive immune cell therapy in breast cancer model using cell membrane labeling. PLoS One. 2014;9:e109162.

80. Koehne G, Doubrovin M, Doubrovina E, et al. Serial in vivo imaging of the targeted migration of human HSV-TK-transduced antigen-specific lymphocytes. Nat Biotechnol. 2003;21:405-413.

81. Chewning JH, Dugger KJ, Chaudhuri TR, Zinn KR, Weaver CT. Bioluminescence-based visualization of CD4 $\mathrm{T}$ cell dynamics using a $\mathrm{T}$ lineage-specific luciferase transgenic model. BMC Immunol. 2009;10:44.

82. Kim H, Peng G, Hicks JM, et al. Engineering human tumor-specific cytotoxic T cells to function in a hypoxic environment. Mol Ther. 2008;16:599-606.

83. Shu CJ, Radu CG, Shelly SM, et al. Quantitative PET reporter gene imaging of $\mathrm{CD} 8+\mathrm{T}$ cells specific for a melanoma-expressed self-antigen. Int Immunol. 2009;21:155-165.

84. Dotti G, Tian M, Savoldo B, et al. Repetitive noninvasive monitoring of HSV1tk-expressing $\mathrm{T}$ cells intravenously infused into nonhuman primates using positron emission tomography and computed tomography with ${ }^{18}$ F-FEAU. Mol Imaging. 2009;8:230-237.

85. Thorek DLJ, Tsao PY, Arora V, et al. In vivo, multimodal imaging of B cell distribution and response to antibody immunotherapy in mice. PLoS One. 2010;5:e10655.

86. Paik JY, Lee KH, Byun SS, Choe YS, Kim BT. Use of insulin to improve $\left[{ }^{18} \mathrm{~F}\right]$ fluorodeoxyglucose labelling and retention for in vivo positron emission tomography imaging of monocyte trafficking. Nucl Med Commun. 2002;23:551-557.

87. Kang S, Lee HW, Jeon YH, et al. Combined fluorescence and magnetic resonance imaging of primary macrophage migration to sites of acute inflammation using nearinfrared fluorescent magnetic nanoparticles. Mol Imaging Biol. 2015;17:643-651.
88. Gramoun A, Crowe LA, Maurizi L, et al. Monitoring the effects of dexamethasone treatment by MRI using in vivo iron oxide nanoparticle-labeled macrophages. Arthritis Res Ther. 2014;16:R131.

89. Daldrup-Link HE, Golovko D, Ruffell B, et al. MRI of tumor-associated macrophages with clinically applicable iron oxide nanoparticles. Clin Cancer Res. 2011;17:5695-5704.

90. Yang CY, Tai MF, Lin CP, et al. Mechanism of cellular uptake and impact of ferucarbotran on macrophage physiology. PLoS One. 2011;6:e25524.

91. Raynal I, Prigent P, Peyramaure S, et al. Macrophage endocytosis of superparamagnetic iron oxide nanoparticles: mechanisms and comparison of ferumoxides and ferumoxtran-10. Invest Radiol. 2004;39:56-63.

92. Kirschbaum K, Sonner JK, Zeller MW, et al. In vivo nanoparticle imaging of innate immune cells can serve as a marker of disease severity in a model of multiple sclerosis. Proc Natl Acad Sci USA. 2016;113:13227-13232.

93. Keliher EJ, Yoo J, Nahrendorf M, et al. ${ }^{89} \mathrm{Zr}$-labeled dextran nanoparticles allow in vivo macrophage imaging. Bioconjug Chem. 2011;22:2383-2389.

94. Lee HW, Jeon YH, Hwang MH, et al. Dual reporter gene imaging for tracking macrophage migration using the human sodium iodide symporter and an enhanced firefly luciferase in a murine inflammation model. Mol Imaging Biol. 2013;15:703-712.

95. Choi YJ, Oh SG, Singh TD, et al. Visualization of the biological behavior of tumor-associated macrophages in living mice with colon cancer using multimodal optical reporter gene imaging. Neoplasia. 2016;18:133-141.

96. Seo JH, Jeon YH, Lee YJ, et al. Trafficking macrophage migration using reporter gene imaging with human sodium iodide symporter in animal models of inflammation. J Nucl Med. 2010;51:1637-1643.

97. Ridolfi R, Riccobon A, Galassi R, et al. Evaluation of in vivo labelled dendritic cell migration in cancer patients. J Transl Med. 2004;2:27.

98. De Vries IJM, Krooshoop DJEB, Scharenborg NM, et al. Effective migration of antigen-pulsed dendritic cells to lymph nodes in melanoma patients is determined by their maturation state. Cancer Res. 2003;63:12-17.

99. Ahrens ET, Flores R, Xu H, Morel PA. In vivo imaging platform for tracking immunotherapeutic cells. Nat Biotechnol. 2005;23:983-987.

100. Baumjohann D, Hess A, Budinsky L, et al. In vivo magnetic resonance imaging of dendritic cell migration into the draining lymph nodes of mice. Eur J Immunol. 2006;36:2544-2555.

101. Noh Y-W, Lim YT, Chung BH. Noninvasive imaging of dendritic cell migration into lymph nodes using near-infrared fluorescent semiconductor nanocrystals. FASEB J. 2008;22:3908-3918.

102. Olasz EB, Lang L, Seidel J, et al. Fluorine-18 labeled mouse bone marrowderived dendritic cells can be detected in vivo by high resolution projection imaging. J Immunol Methods. 2002;260:137-148.

103. Ahrens ET, Helfer BM, O'Hanlon CF, Schirda C. Clinical cell therapy imaging using a perfluorocarbon tracer and fluorine-19 MRI. Magn Reson Med. 2014;72:1696-1701.

104. Stoll S, Delon J, Tilmann BM, Germain RN. Dynamic imaging of T celldendritic cell interactions in lymph nodes. Science. 2002;296:1873-1876.

105. Lee HW, Yoon SY, Singh TD, et al. Tracking of dendritic cell migration into lymph nodes using molecular imaging with sodium iodide symporter and enhanced firefly luciferase genes. Sci Rep. 2015;5:9865.

106. Kim HS, Woo J, Lee JH, et al. In vivo tracking of dendritic cell using MRI reporter gene, ferritin. PLoS One. 2015;10:e0125291.

107. Schimmelpfennig $\mathrm{CH}$, Schulz S, Arber C, et al. Ex vivo expanded dendritic cells home to T-cell zones of lymphoid organs and survive in vivo after allogeneic bone marrow transplantation. Am J Pathol. 2005;167:1321-1331.

108. Daldrup-Link HE, Meier R, Rudelius M, et al. In vivo tracking of genetically engineered, anti-HER2/neu directed natural killer cells to HER2/neu positive mammary tumors with magnetic resonance imaging. Eur Radiol. 2005;15:4-13.

109. Tavri S, Jha P, Meier R, et al. Optical imaging of cellular immunotherapy against prostate cancer. Mol Imaging. 2009;8:15-26.

110. Melder RJ, Brownell AL, Shoup TM, Brownell GL, Jain RK. Imaging of activated natural killer cells in mice by positron emission tomography : preferential uptake in tumors. Cancer Res. 1993;53:5867-5871.

111. Meller B, Frohn C, Brand JM, et al. Monitoring of a new approach of immunotherapy with allogenic ${ }^{111}$ In-labelled NK cells in patients with renal cell carcinoma. Eur J Nucl Med Mol Imaging. 2004;31:403-407.

112. Kurtz DM, Gambhir SS. Tracking cellular and immune therapies in cancer. $A d v$ Cancer Res. 2014;124:257-296.

113. Chatterjee S, Lesniak WG, Gabrielson M, et al. A humanized antibody for imaging immune checkpoint ligand PD-L1 expression in tumors. Oncotarget. 2016;7:10215-10227.

114. Arlauckas SP, Garris CS, Kohler RH, et al. In vivo imaging reveals a tumorassociated macrophage-mediated resistance pathway in anti-PD-1 therapy. Sci Transl Med. 2017;9:3604. 